\title{
INFLUENCE OF ASPECT RATIO IN THE TURBULENT CONVECTION IN CAVITIES
}

\author{
R. M. Guimarães ${ }^{\mathrm{a}}$, \\ V. C. Mariania ${ }^{a}$, \\ and K. C. Mendonça ${ }^{b}$ \\ ${ }^{a}$ Departamento de Engenharia Mecânica \\ Pontifícia Universidade Católica do Paraná, \\ Curitiba, Paraná - Brasil \\ ${ }^{\mathrm{b}}$ LaSIE - University of La Rochelle \\ Av. Michel Crépeau \\ 17042 La Rochelle Cedex 1 - France \\ ABSTRACT \\ The purpose of this study is to know the air distribution in a conditioned \\ room, through the numerical investigation of the influence of aspect ratio in \\ the thermal and fluid dynamics behavior of a turbulent flow. To achieve that \\ objective, some simulations were done of the flow inside a rectangular \\ room, where the air enters through an opening in the top of one wall and \\ leaves the room through an opening in the bottom of the opposite wall. The \\ Reynolds mean equations are used, with the turbulence model RSM BSL \\ (Reynolds Stress Model - Baseline) to solve four cases, with different \\ geometries. It was concluded that, in general, the turbulence model used in \\ this work is capable to predict quite well the fluid dynamics behavior of the \\ flow, which is influenced by the room length, but not by its width. \\ Received: November 18, 2013 \\ Revised: December 10, 2013 \\ Accepted: December 30, 2013 \\ Keywords: turbulence, CFD, Reynolds Stress Model.
}

\section{NOMENCLATURE}

$h$ height of the inlet slot, $\mathrm{m}$

$H$ height of the room, $\mathrm{m}$

$\mathrm{k}$ turbulent kinetic energy, $\mathrm{m}^{2} / \mathrm{s}^{2}$

$\mathrm{L}$ room length, $\mathrm{m}$

$\mathrm{P}$ pressure, $\mathrm{Pa}$

$\mathrm{R}$ Reynolds number

$t$ height of the outlet opening, $m$

$\mathrm{u}$ component of instantaneous velocity in the direction $\mathrm{x}, \mathrm{m} / \mathrm{s}$

$u^{\prime}$ fluctuations of velocity in the direction $x, m / s^{2}$

$\mathrm{U}$ mean velocity in the directions $\mathrm{x}, \mathrm{m} / \mathrm{s}$

$\mathrm{U}_{0} \quad$ velocity in the room inlet in the direction $\mathrm{x}, \mathrm{m} / \mathrm{s}$

$\mathrm{v}$ component of instantaneous velocity in the direction $\mathrm{y}, \mathrm{m} / \mathrm{s}$

$\mathrm{v}^{\prime}$ fluctuations of velocity in the direction $\mathrm{y}, \mathrm{m} / \mathrm{s}^{2}$

$\mathrm{V}$ mean velocity in the directions $\mathrm{y}, \mathrm{m} / \mathrm{s}$

$\mathrm{V}_{0} \quad$ velocity in the room inlet in the direction $\mathrm{y}, \mathrm{m} / \mathrm{s}$

$\mathrm{w}$ component of instantaneous velocity in the direction $\mathrm{z}, \mathrm{m} / \mathrm{s}$

$\mathrm{w}^{\prime}$ fluctuations of velocity in the direction $\mathrm{z}, \mathrm{m} / \mathrm{s}^{2}$

$\mathrm{W}_{0}$ velocity in the room inlet in the direction $\mathrm{z}, \mathrm{m} / \mathrm{s}$

$\mathrm{W}$ room width, $\mathrm{m}$

$\mathrm{x}$ cartesian coordinate in the direction $\mathrm{x}, \mathrm{m}$

$\mathrm{y}$ cartesian coordinate in the direction $\mathrm{y}, \mathrm{m}$

$\mathrm{z} \quad$ cartesian coordinate in the direction $\mathrm{z}, \mathrm{m}$

\section{Greek symbols}

$\varepsilon$ dissipation of turbulent kinetic energy, $\mathrm{m}^{2} / \mathrm{s}^{3}$

$\mu \quad$ dynamic viscosity, $\mathrm{kg} /(\mathrm{ms})$

$\mu_{\mathrm{t}} \quad$ turbulent dynamic viscosity, $\mathrm{kg} /(\mathrm{ms})$

V kinematic viscosity, $\mathrm{m}^{2} / \mathrm{s}$

$v_{\mathrm{t}}$ turbulent kinematic viscosity, $\mathrm{m}^{2} / \mathrm{s}$

$\rho$ specific weight, $\mathrm{kg} / \mathrm{m}^{3}$ $\omega$ rate of dissipation of turbulent kinetic energy, $\mathrm{m}^{2} / \mathrm{s}^{3}$

\section{INTRODUCTION}

A very important piece of the population spends most part of the day inside enclosed places, which normally are conditioned to offer adequate sanitary and comfort conditions to the occupants. However, the available air conditioning systems produce heterogeneous conditions of air properties that can be unpleasant for the occupants, even when the global thermal perception is satisfactory. Besides that, the airflow impacts the heat and mass exchanges between air and the environment envelope, and consequently the energy consumption. The air quality inside an enclosed environment also depends on the airflow, because the pollutant sources can get concentrated in some places and affect the occupants in different ways. Thus, in order to design environments energetically efficient, maintaining adequate comfort and quality conditions to the occupants, it is necessary to determine air and its properties distribution inside the room.

Detailed information about the thermal and fluid dynamics behavior of airflows inside conditioned environments can be obtained through Computational Fluid Dynamics (CFD) that can be described as the numerical simulation of all physical and chemical processes present in the airflow.

Other authors have done experimental and numerical studies about the prediction of the airflow inside environments with natural, forced or mixed convection. Nielsen (1976) has investigated experimentally the isothermal and non-isothermal airflows in conditioned rooms and has obtained 
velocity and temperature results for two and three dimensional environments that are used as reference in this study. In 1990, Nielsen studied the same model of 1976 to obtain dimensionless mean velocity and turbulence intensity results. Gan (1995) has used CFD to predict the thermal comfort in a room with forced convection, in order to optimize the air conditioning system. Chen (1996) has used different turbulence models to determine the behavior of airflow inside rooms with natural, forced or mixed convection and noticed that the Reynolds Stress Model (RSM) was very efficient, but required more computational resources than standard k- $\varepsilon$ model. Costa et al. (2000) have studied the influence of geometric, dynamics and thermal parameters in the behavior of the two dimensional turbulent airflow, through numerical simulation using the model defined in a previous study of the authors, Costa et al. (1999). Schalin and Nielsen (2004) have analyzed the performance of two turbulence models in the fluid dynamics prediction of an isothermal airflow, and have concluded that the Reynolds Stress Model presented better results than standard k- $\varepsilon$ model. Susin et al. (2009) have studied the same model of Nielsen (1976), using three different two-equation models, and then compared the numerical results to the experimental of the literature. The authors have realized that all the models had well predicted the mean flow, but not the turbulence intensity, because of the anisotropy assumption of the models used.

The main objective of this study is to investigate numerically the influence of geometry aspect ratio that means the ratio between the width and the length of the room, in the thermal and fluid dynamics behavior of the isothermal turbulent flow inside it. Thus, this work aims to contribute with the improvement of air quality, thermal comfort of occupants and air conditioning systems efficiency in enclosed places, through the airflow analysis. To achieve those objectives, the airflow is simulated in CFD, using the Baseline Reynolds Stress Model, which was chosen because it is one of the most accurate turbulence models. This work also analyzes if this turbulence model shows some advantages comparing to more common ones, like two-equation turbulence models.

\section{MATHEMATICAL MODEL}

The airflow inside the room in study is described by the continuity equation, together with the energy conservation equation and the Reynolds mean equations, which are obtained by the time-averaging of Navier-Stokes momentum equations (Launder and Spalding, 1975; Versteeg and Malalasekera, 1995).

$$
\frac{\partial \rho}{\partial \mathrm{t}}+\operatorname{div}(\rho \mathrm{U})=0
$$

$$
\begin{aligned}
& \frac{\partial \mathrm{U}}{\partial \mathrm{t}}+\operatorname{div}(\mathrm{UU})=-\frac{1}{\rho} \frac{\partial \mathrm{P}}{\partial \mathrm{x}}+v \operatorname{div} \operatorname{grad} \mathrm{U} \\
& +\left[-\frac{\partial \overline{u^{\prime 2}}}{\partial \mathrm{x}}-\frac{\partial \overline{u^{\prime} v^{\prime}}}{\partial y}-\frac{\partial \overline{u^{\prime} w^{\prime}}}{\partial \mathrm{z}}\right] \\
& \frac{\partial V}{\partial \mathrm{t}}+\operatorname{div}(\mathrm{VU})=-\frac{1}{\rho} \frac{\partial \mathrm{P}}{\partial \mathrm{y}}+v \operatorname{div} \operatorname{grad} \mathrm{V} \\
& +\left[\begin{array}{c}
\left.-\frac{\partial v^{\prime 2}}{\partial y}-\frac{\partial \overline{u^{\prime} v^{\prime}}}{\partial x}-\frac{\partial \overline{v^{\prime} w^{\prime}}}{\partial \mathrm{z}}\right] \\
\frac{\partial \mathrm{W}}{\partial \mathrm{t}}+\operatorname{div}(\mathrm{WU})=-\frac{1}{\rho} \frac{\partial \mathrm{P}}{\partial \mathrm{z}}+v \operatorname{div} \operatorname{grad} \mathrm{W} \\
\left.+\frac{\partial w^{\prime 2}}{\partial \mathrm{z}}-\frac{\partial u^{\prime} w^{\prime}}{\partial x}-\frac{\partial v^{\prime} w^{\prime}}{\partial y}\right]
\end{array}\right]
\end{aligned}
$$

The application of this operator despise the details of all turbulent fluctuations, what results in six additional terms, the Reynolds stresses, which can be predicted by a turbulence model. The BSL Reynolds Stress Model applies the transport equation for the dissipation of kinetic energy $(\omega)$, and for the six Reynolds stresses equations $\left(\mathrm{R}_{\mathrm{ij}}\right)$, once it considers the turbulent viscosity as anisotropic.

$$
\begin{gathered}
\rho U_{j} \frac{\partial \omega}{\partial x_{j}}=\frac{\partial}{\partial x_{j}}\left[\left(\mu+\frac{\mu_{t}}{\sigma_{\omega}}\right) \frac{\partial \omega}{\partial x_{j}}\right]+ \\
\alpha \mu_{t} \frac{\omega}{\mu_{t}}\left(\frac{\partial U_{i}}{\partial x_{j}}+\frac{\partial U_{i}}{\partial x_{j}}\right) \frac{\partial U_{i}}{\partial x_{j}}-\beta \rho \omega^{2}
\end{gathered}
$$

$$
\frac{D R_{i j}}{D_{t}}=P_{i j}+D_{i j}-\varepsilon_{i j}+\Pi_{i j}+\Omega_{i j}
$$

where $\rho$ is the specific weight, $\mathrm{U}, \mathrm{V}$ and $\mathrm{W}$ are the mean velocity in the directions $\mathrm{x}, \mathrm{y}$ and $\mathrm{z}, \mathrm{P}$ is the pressure and $\mathrm{u}^{\prime}, \mathrm{v}^{\prime}$ and $\mathrm{w}^{\prime}$ are the fluctuations of velocity in the directions $\mathrm{x}, \mathrm{y}$ and $\mathrm{z}$. And $\mathrm{R}_{\mathrm{ij}}$ are the Reynolds stresses, $P_{i j}$ is the rate of production of $R_{i j}$, $D_{i j}$ is the transport of $R_{i j}$ by diffusion, $\varepsilon_{i j}$ is the rate of dissipation of $R_{i j}, \Pi_{i j}$ is the transport of $R_{i j}$ due to turbulent pressure-strain interactions and $\Omega_{\mathrm{ij}}$ is the transport of $\mathrm{R}_{\mathrm{ij}}$ due to rotation (Voigt, 2000). 


\section{NUMERICAL MODEL}

\section{Physical Model}

The physical model used in this study is based on the experimental device created by Nielsen (1976, 1990), that represents a room where the air enters horizontally parallel to the ceiling (left wall) and leaves through an opening near the floor (right wall), as shown in Fig. 1.

The height of the room, $\mathrm{H}$, is $3 \mathrm{~m}$, the height of the inlet slot, $h$, is $0.168 \mathrm{~m}$ and height of the outlet opening, $t$, is $0.48 \mathrm{~m}$. To analyze the influence of the aspect ratio in the behavior of the flow, the ratios $\mathrm{L} / \mathrm{H}$ and $\mathrm{W} / \mathrm{H}$ varies case to case, according to Tab. 1 .

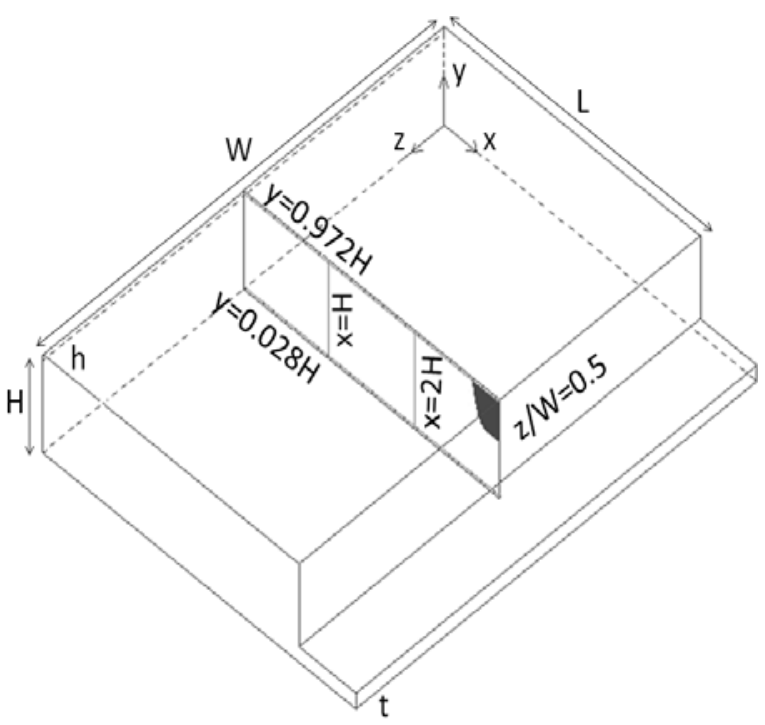

Figure 1. Schematic representation of the model.

Table 1. Aspect ratio of the geometry in the cases studied.

\begin{tabular}{c|c|c}
\hline Case & L/H & W/H \\
\hline 1 & 3 & 4.7 \\
2 & 1 & 1 \\
3 & 3 & 1 \\
4 & 4.7 & 1 \\
\hline
\end{tabular}

The case 1 has the exact same dimensions of the device studied by Nielsen $(1976,1990)$, thus the validation of the present model is made by comparing the results of dimensionless mean velocity and turbulent intensity of this case to the experimental data obtained by that author. The analysis are made in four lines in the symmetry plan, being two horizontals, positioned in $\mathrm{y}=0.028 \mathrm{H}$ and $\mathrm{y}=0.972 \mathrm{H}$, and two verticals positioned in $\mathrm{x}=\mathrm{H}$ and $\mathrm{x}=2 \mathrm{H}$, according to Fig. 1.
After the validation, the results are compared between the cases 1 and 3, to analyze the influence of the width of the room, $\mathrm{W}$, and between the cases 2,3 and 4 , to analyze the influence of the length of the room, $\mathrm{L}$, in the resulting airflow.

\section{Spatial Discretization}

At least three meshes are created for each case, in order to define the most adequate spatial discretization to simulate the airflow in study. To initiate the meshes development, the computational domain is created through the software ANSYS ICEM CFD (Version 11), and divided into four blocks that distinguish the inlet, the outlet and the outlet slot. After this, the meshes are created by the definition of three parameters, the distance between the first node and the wall, the expansion factor, considered as 1.25 for all the directions, and the kind of function used by the software to distribute the nodes, considered as exponential. The characteristics of the three meshes used in case 1 are shown in Tab. 2 .

Table 2. Characteristics of the three meshes used in case 1 .

\begin{tabular}{c|c|c|c}
\hline Case & Meshes & $\begin{array}{c}\text { Discretization } \\
(\mathbf{x}, \mathbf{y}, \mathbf{z})\end{array}$ & $\begin{array}{c}\text { Number of } \\
\text { Elements }\end{array}$ \\
\hline & 1 & $30 \times 20 \times 50$ & 42916 \\
1 & 2 & $60 \times 40 \times 50$ & 145680 \\
& 3 & $60 \times 80 \times 50$ & 284672 \\
\hline
\end{tabular}

Table 2 shows that mesh 1 is coarse and mesh 3 is the finest, according to the number of elements. The mesh 2 is defined through the analysis of $\mathrm{y}^{+}$ results of mesh 1 and its refinement in $x$ and $y$ directions. The same way, mesh 3 is defined through the refinement of mesh 2 in $y$ direction. Fig. 2 shows the details of the three meshes discretization in the lateral plane. The meshes for the other cases were defined through the same methodology, using $\mathrm{y}^{+}$ results to help the refinement.

In order to calculate the advection terms in the finite-volume equations, the advection scheme must be chosen, because it significantly impacts the convergence and accuracy of the numerical results. The advection scheme can be of first order precision, upwind, second order precision, high resolution, or a intermediate scheme, defined through the blend factor. Upwind advection scheme is robust and stable, although less accurate than the high resolution scheme, which considers a correction factor in the advection terms. Thus, in this study, the upwind scheme is used at first for all the cases, in order to obtain the initial results for the next simulations, where the blend factor is increased until the high resolution scheme can be used. 

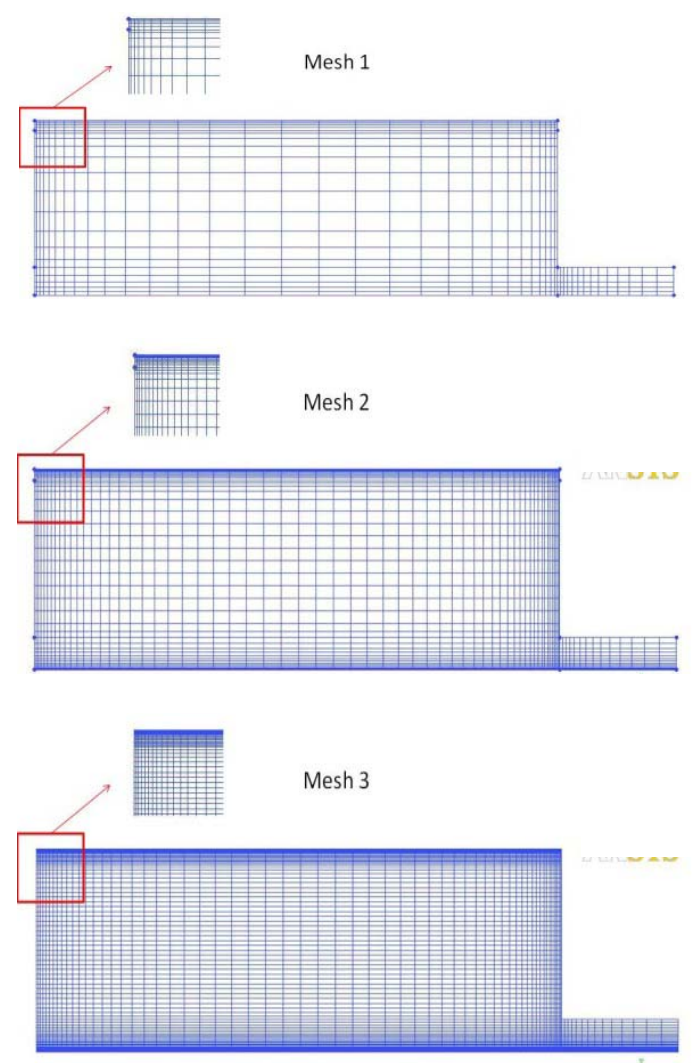

Figure 2. Lateral section of the three meshes used in case 1 .

\section{Boundary Conditions}

The boundary conditions are defined so that the governing equations of the airflow can be solved. The boundary condition in the inlet is prescribed velocity, which can be obtained through the definition of Reynolds number, based on the height of the inlet slot, $\mathrm{Re}=\rho \mathrm{hU}_{0} / \mu$. $\mathrm{Re}=4700, \rho=1.166 \mathrm{~kg} / \mathrm{m}^{3}$ and $\mu=1.7825 \times 10-5$, then $U_{0}=0.4277 \mathrm{~m} / \mathrm{s}$. Considering that the inlet airflow is horizontal, the velocity in the other directions are null. According to the equations for the turbulent kinetic energy, $\mathrm{k}_{0}$, and the dissipation of turbulent kinetic energy, $\varepsilon_{0}$, presented by Nielsen (1990), $\mathrm{k}_{0}=0.000438986 \mathrm{~m}^{2} / \mathrm{s}^{2}$ and $\varepsilon_{0}=0.000547477 \mathrm{~m}^{2} / \mathrm{s}^{3}$. Besides that, the pressure inside and outside the room are $101325 \mathrm{~Pa}$.

In the walls, the velocity are null, $\mathrm{U}=\mathrm{V}=\mathrm{W}=0$, then $\mathrm{k}_{0}=0$ and $\varepsilon_{0}=0$. In the outlet, the relative pressure is null and the flow is considered fully developed, as well as in the symmetry plan, then $\partial U / \partial \hat{n}=\partial V / \partial \hat{n}=\partial W / \partial \hat{n}=\partial k / \partial \hat{n}=\partial \varepsilon / \partial \hat{n}=$ $\partial \omega / \partial \hat{n}=0$

\section{MATHEMATICAL MODEL}

\section{Numerical Validation}

In order to validate the numerical simulations of case 1 , the numerical results obtained by the three meshes are compared with the experimental data (Nielsen, 1976) and the numerical results obtained through the $\mathrm{k}-\omega$ turbulence model (Susin et al., 2009), in terms of dimensionless mean velocity and turbulent intensity, as shown in Fig. 3 and 4.
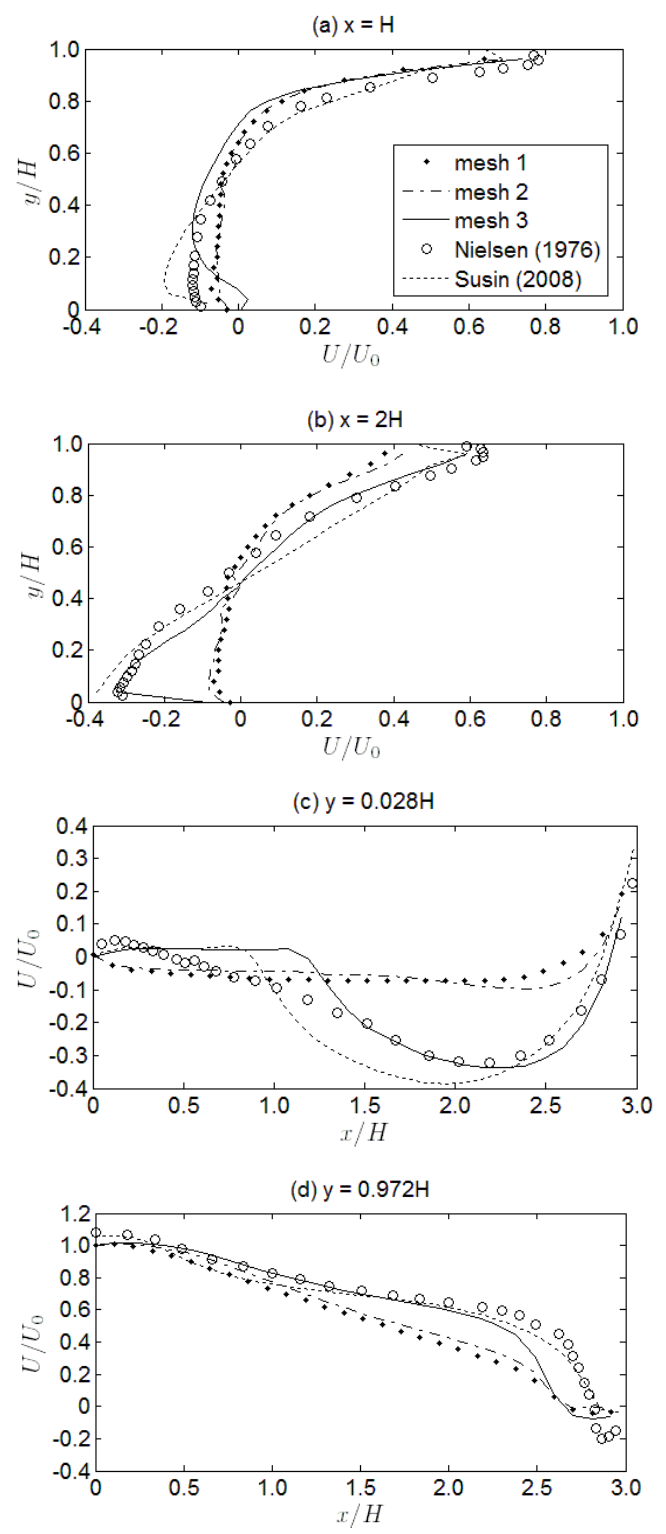

Figure 3. Dimensionless mean velocity in the symmetry plan.

In general, Fig. 3 shows that meshes 1 and 2 have obtained similar results and mesh 3 could predict the airflow mean velocity more accurately than the others, in all regions. However, the difference between numerical and experimental results near the floor, where $0.5<\mathrm{x} / \mathrm{H}<1.5$, and near the ceiling, where $2.5<\mathrm{x} / \mathrm{H}<3$, shows that the velocity was underestimated by the model. Comparing mesh 3 velocity results to the ones obtained through $\mathrm{k}-\omega$ turbulence model (Susin et al., 2009), it is noticed that both models presented similar behaviors in $\mathrm{x}=\mathrm{H}$ 
and $\mathrm{x}=2 \mathrm{H}$, although near the floor RSM has underestimated the velocity while $\mathrm{k}-\omega$ turbulence model has overestimated it. Fig. 3 (c) also shows that RSM has estimated the velocity much better than $\mathrm{k}-\omega$ turbulence model in $1.5<\mathrm{x} / \mathrm{H}<2.3$.

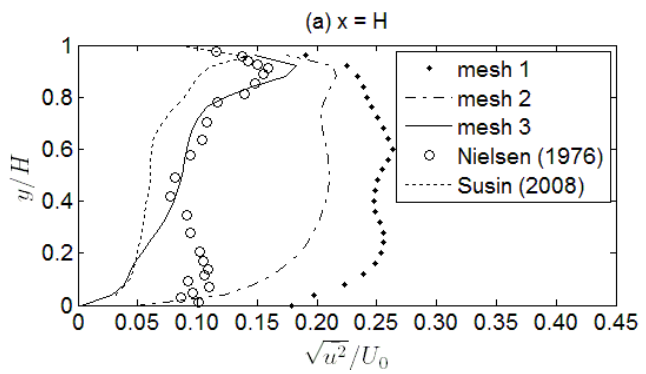

(b) $\mathrm{x}=2 \mathrm{H}$

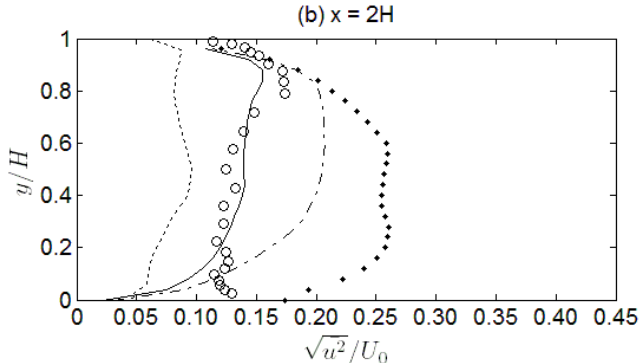

(c) $y=0.028 \mathrm{H}$

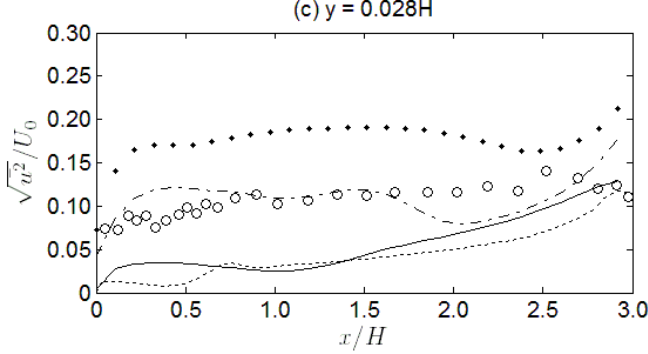

(d) $y=0.972 \mathrm{H}$

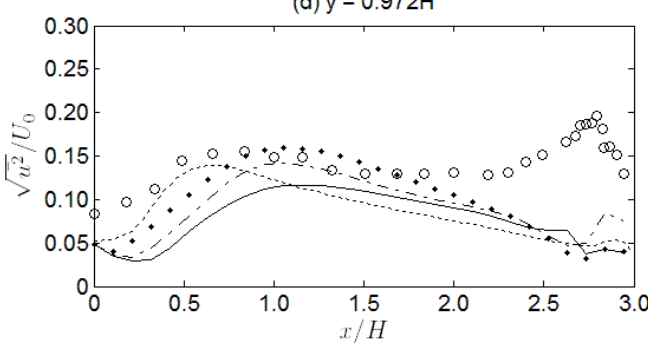

Figure 4. Dimensionless turbulent intensity in the symmetry plan.

It is noticed in Fig. 4 that mesh 3 was the only one capable to predict the turbulence intensity in $\mathrm{x}=\mathrm{H}$, though it presents discrepancy to the experimental results as it gets near to the floor, in $\mathrm{y} / \mathrm{H}<0.4$. In $\mathrm{x}=2 \mathrm{H}$, the same behavior occurs, but only in $\mathrm{y} / \mathrm{H}<0.2$. Fig. 4 (c) shows that mesh 2 has obtained good results near the floor through all the length of the room, but analyzing Fig. 4 (a) and (b), it is possible to notice that the similarity between those results is only punctual. Fig. 4 (d) shows that mesh 1 presented the best results compared to the experimental ones near the ceiling, although in $\mathrm{x} / \mathrm{H}>2$, none of them, not even $\mathrm{k}-\omega$ turbulence model, were able to predict the turbulence intensity. Comparing mesh 3 turbulence intensity results to the ones obtained through $\mathrm{k}-\omega$ turbulence model (Susin et al., 2009), it is possible to say that RSM has predicted more accurately than the other model.

To summarize, Figures 3 and 4 shows that the mesh 3 could predict the mean velocity and turbulent intensity of the airflow with precision, but presented some difficulty near the right wall and the floor, as well as the k- $\omega$ turbulence model (Susin et al., 2009).

\section{Numerical Validation}

The results of dimensionless mean velocity and turbulent intensity are compared between the cases 1 and 3 , to analyze the influence of the width of the room, $\mathrm{W}$, and between the cases 2,3 and 4 , to analyze the influence of the length of the room, $\mathrm{L}$, in the airflow behavior, as shown in Fig. 5 to 8 .
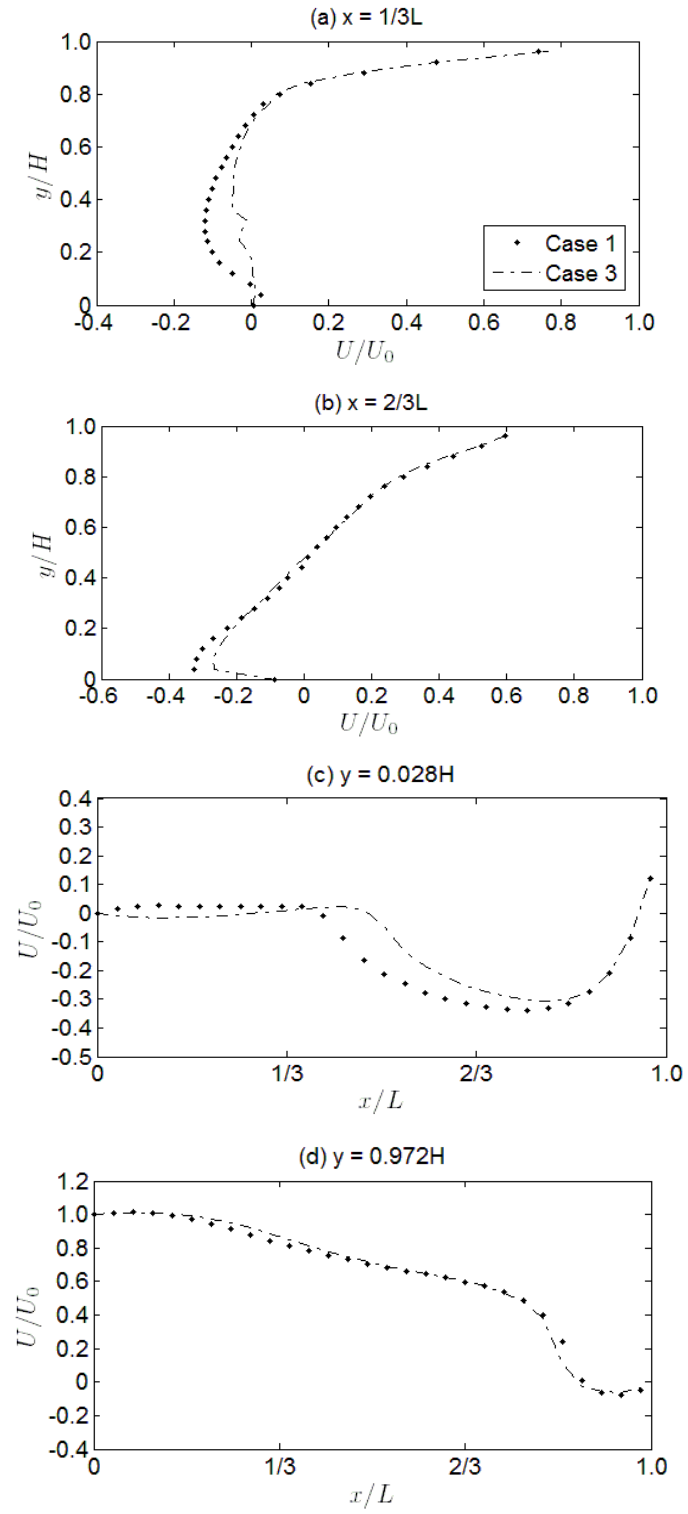

Figure 5. Dimensionless mean velocity in the symmetry plan, for cases 1 and 3 . 
(a) $x=1 / 3 \mathrm{~L}$

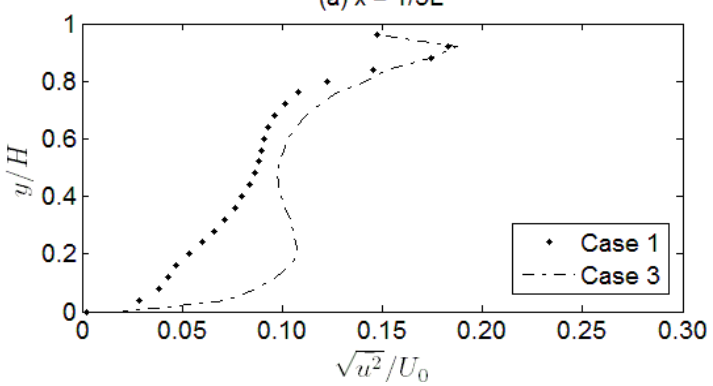

(b) $x=2 / 3 L$

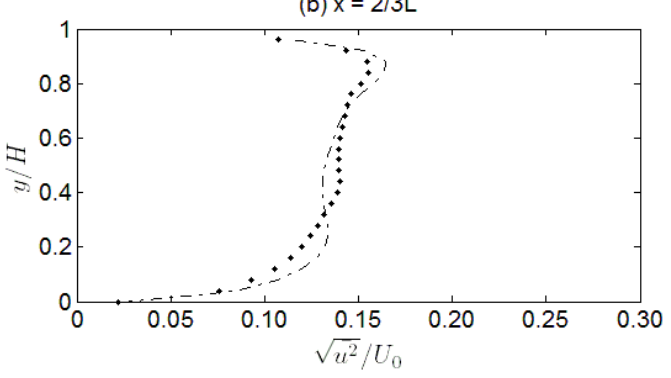

(c) $y=0.028 \mathrm{H}$

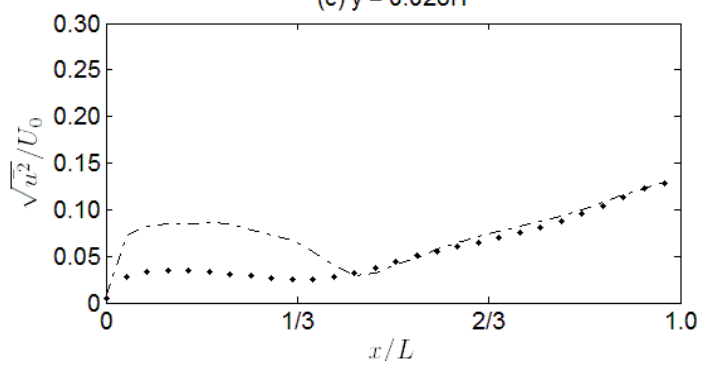

(d) $y=0.972 \mathrm{H}$

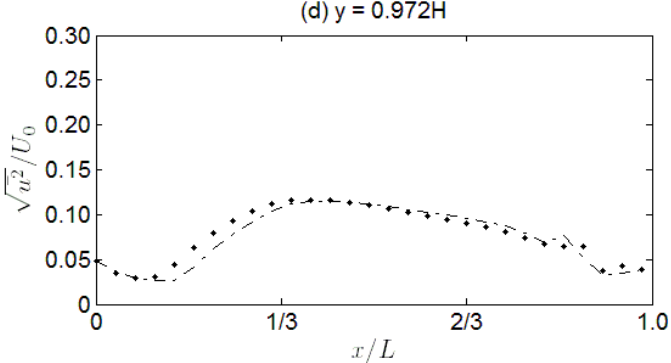

Figure 6. Dimensionless mean turbulent intensity in the symmetry plan, for cases 1 and 3 .

Figures 5 and 6 shows that the mean velocity and turbulent intensity results of cases 1 and 3 are very similar, which indicates that the width of the room, $\mathrm{W}$, does not influence the behavior of the flow.

\section{(b) $x=2 / 3 L$}

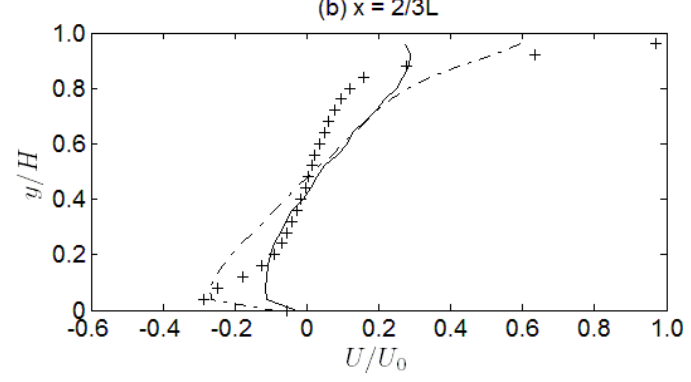

(c) $y=0.028 \mathrm{H}$

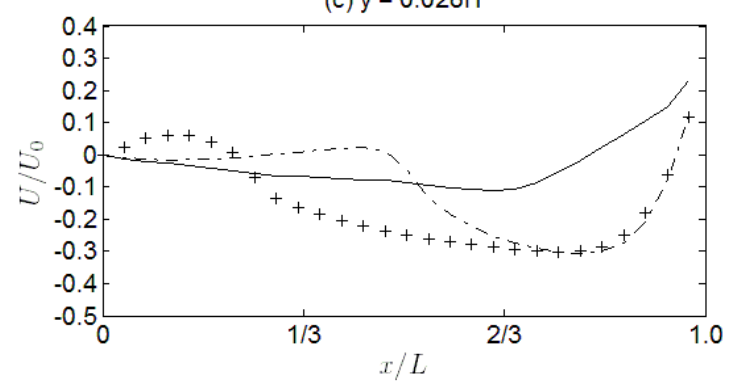

(d) $y=0.972 \mathrm{H}$

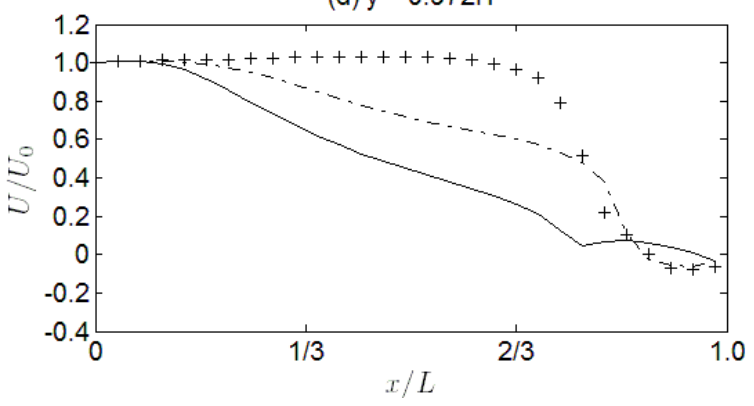

Figure 7. Dimensionless mean velocity in the symmetry plan, for cases 2,3 and 4 .

(a) $x=1 / 3 L$

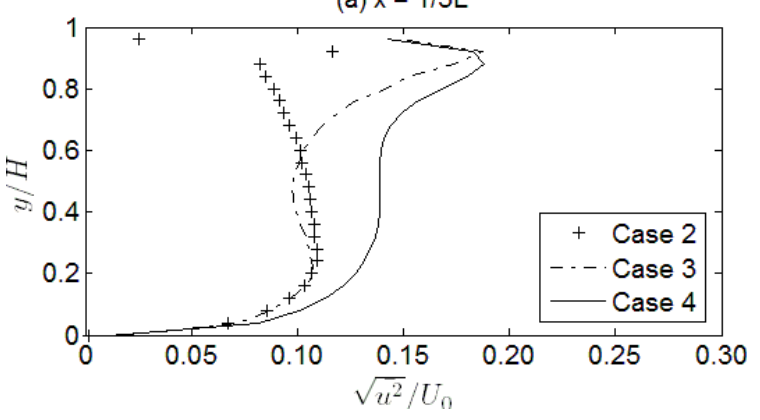

(b) $x=2 / 3 \mathrm{~L}$

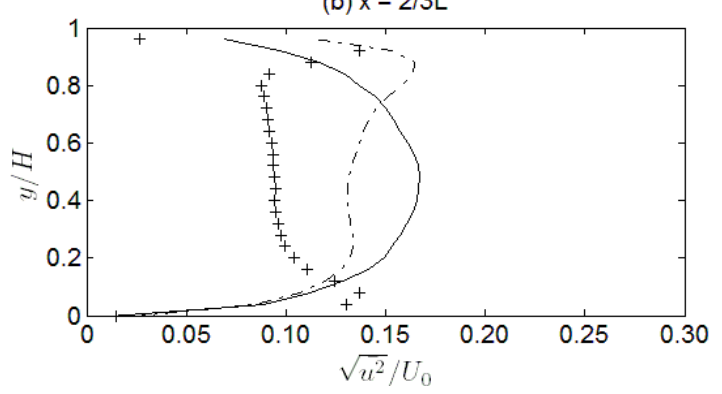

(c) $y=0.028 \mathrm{H}$

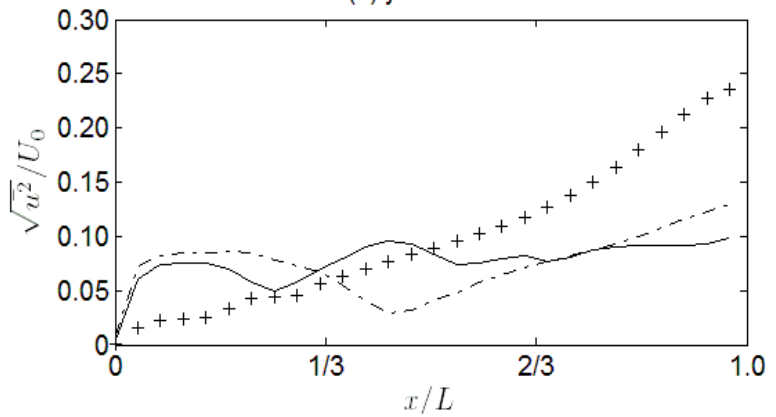




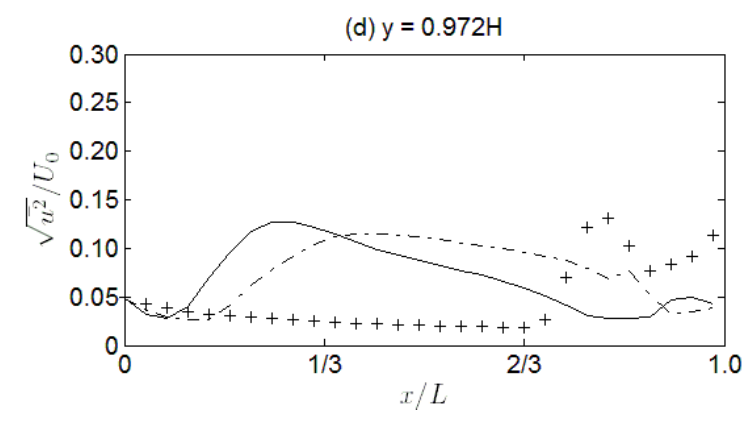

Figure 8. Dimensionless mean turbulent intensity in the symmetry plan, for cases 2,3 and 4 .

The comparison of the mean velocity and turbulent intensity results of cases 2, 3 and 4 shows visible differences among them. It is possible to realize that the point where the inlet velocity decreases varies case by case. It is also noticed that the turbulence intensity presents three dimensional effects. Thus, it is concluded that the length of the room, L, influences the behavior of the flow inside it.

\section{CONCLUSIONS}

In the validation, it was concluded that, in general, the turbulence model used in this work, Baseline Reynolds Stress Model, is capable to predict quite well the fluid dynamics behavior of the flow, even though the mean velocity had been underestimated in some regions of the ceiling and floor of the room. After the validation, the influence of aspect ratio in the flow was analyzed, changing the width and length of the room. It was concluded that the behavior of the flow is influenced by the room length, because the dimensionless profiles of velocity and turbulence intensity were different between the cases with different lengths, but not by the room width.

\section{REFERENCES}

Chen, Q., 1996, Prediction of Room air Motion by Reynolds-Stress Models, Building and Environment, Vol. 31, pp. 233-244.

Costa, J. J., Oliveira, L. A., and Blay, D., 1999, Test of Several Versions for the k-e type Turbulence Modeling of Internal Mixed Convection Flows, International Journal of Heat and Mass Transfer, Vol. 42, pp. 4391-4409.

Costa, J. J., Oliveira, L. A., and Blay, D., 2000, Turbulent Airflow in a Room with a Two-Jet Heating-Ventilation System - a Numerical Parametric Study, Energy and Buildings, Vol. 32, pp. 327-343.

Gan, G., 1995, Evaluation of Room air Distribution Systems using Computational Fluid Dynamics, Energy and Buildings, Vol. 23, pp. 83-93.

Launder, B. E., and Spalding, D. B., 1975, Progress in the Development of a Reynolds-Stress
Turbulence Closure, Journal of Fluid Mechanics, Vol. 68, pp. 537-566.

Nielsen, P. V., 1990, Specification of a TwoDimensional Test Case, Technical Report, International Energy Agency, Annex 20: Air Flow Pattern Within Buildings.

Nielsen, P. V., 1976, Flow in air Conditioned Rooms. Model Experiments and Numerical Solution of the Flow Equations, Doctoral Thesis, Technical University of Denmark, Copenhagen.

Schalin, A., and Nielsen, P. V., 2004, Impact of Turbulence Anisotropy Near Walls in Room Airflow, Indoor Air, Vol. 14, pp. 159-168.

Susin, R. M., Lindner, G. A., Mariani, V. C., and Mendonça, K. C., 2009, Evaluating the Influence of the width of Inlet Slot on the Prediction of Indoor Airflow: Comparison with Experimental Data, Building and Environment, Vol. 44, pp. 971-986.

Versteeg, K., and Malalasekera, W., 1995, An Introduction to Computational Fluid Dynamics, Longman Scientific \& Technical, New York.

Voigt, L. K., 2000, Comparison Of Turbulence Models For Numerical Calculation of Airflow in an Annex 20 Room, et-Afm 2000-01, Technical Report, University Of Denmark, Pp. 1-46. 